\title{
ChSte7 Is Required for Vegetative Growth and Various Plant Infection Processes in Colletotrichum higginsianum
}

\author{
Qinfeng Yuan, Meijuan Chen, Yaqin Yan, Qiongnan Gu, Junbin Huang, and Lu Zheng \\ The Key Laboratory of Plant Pathology of Hubei Province, Huazhong Agricultural University, Wuhan, Hubei 430070, China \\ Correspondence should be addressed to Lu Zheng; luzheng@mail.hzau.edu.cn
}

Received 29 March 2016; Revised 19 May 2016; Accepted 30 June 2016

Academic Editor: Guo-Tian Li

Copyright (C) 2016 Qinfeng Yuan et al. This is an open access article distributed under the Creative Commons Attribution License, which permits unrestricted use, distribution, and reproduction in any medium, provided the original work is properly cited.

\begin{abstract}
Colletotrichum higginsianum is an important hemibiotrophic phytopathogen that causes crucifer anthracnose in various regions of the world. In many plant-pathogenic fungi, the Stell-Ste7-Fus3/Kss1 kinase pathway is essential to pathogenicity and various plant infection processes. To date, the role of ChSte7 in C. higginsianum encoding a MEK orthologue of Ste7 in Saccharomyces cerevisiae has not been elucidated. In this report, we investigated the function of ChSte7 in the pathogen. The ChSte7 is predicted to encode a 522-amino-acid protein with a S_TKc conserved domain that shares $44 \%$ identity with Ste7 in S. cerevisiae. ChSte7 disruption mutants showed white colonies with irregularly shaped edges and extremely decreased growth rates and biomass productions. The ChSte7 disruption mutants did not form appressoria and showed defects in pathogenicity on leaves of Arabidopsis thaliana. When inoculated onto wounded leaf tissues, the ChSte7 disruption mutants grew only on the surface of host tissues but failed to cause lesions beyond the wound site. In contrast, both the wild-type and complementation strains showed normal morphology, produced appressoria, and caused necrosis on leaves of Arabidopsis. Analysis with qRT-PCR suggested that ChSte7 was highly expressed during the late stages of infection. Taken together, our results demonstrate that $\mathrm{ChSte}$ is involved in regulation of vegetative growth, appressorial formation of C. higginsianum, and postinvasive growth in host tissues.
\end{abstract}

\section{Introduction}

The hemibiotrophic ascomycete fungus Colletotrichum higginsianum is the causal agent of anthracnose disease on a wide range of cruciferous plants, such as Brassica, Raphanus, and the model plant Arabidopsis thaliana [1]. For example, in South China, this fungus usually causes typical water-soaked lesions on leaves of Chinese cabbage (B. parachinensis), leading to $30-40 \%$ yield loss yearly [2]. To invade host tissue, conidia first attach to plant surfaces and germinate to form melanized appressoria. After that, C. higginsianum penetrates the plant cell with high turgor pressure generated in the melanized appressorium, and then large bulbous biotrophic hyphae form in the first infected cell. Finally, the fungus differentiates secondary hyphae to kill host tissues [3].

The C. higginsianum-A. thaliana pathosystem provides an attractive model for dissecting fungal pathogenicity and plant resistance, in which both partners can be genetically manipulated [4]. Genome and transcriptome analyses of $C$. higginsianum infecting $A$. thaliana indicate that this fungus has many virulence factors [5]. To date, just limited molecular determinants of virulence in C. higginsianum have been reported. ChEC effectors are focally secreted from appressorial penetration pores before host invasion, revealing new levels of functional complexity for $C$. higginsianum [6]. Arginine biosynthesis was shown to be critical for early stages of plant infection by C. higginsianum [7]. Ch-MEL1 is required for both appressorial formation and melanin production in C. higginsianum as well as postinvasive growth in host tissues [8]. Chpma2 deletion mutants form fully melanized appressoria but entirely fail to penetrate the host tissue and are nonpathogenic [9]. However, more virulence factors in the model phytopathogen remain to be elucidated and characterized.

Signal transduction is a highly conserved system that enables eukaryotes to sense and respond to extracellular conditions. The mitogen-activated protein kinase (MAPK) cascade is one of the ubiquitous signaling systems in eukaryotes. The cascade is universally composed of three kinase proteins, MAPK-extracellular regulated kinase kinase (MEKK), 
MAPK-extracellular regulated kinase (MEK), and MAPK [10]. Upon perception of an appropriate external stimulus, MEKK phosphorylates MEK, which then phosphorylates MAPK, resulting in enzymatic activation and eventual relay of signal to ultimately activate physiological responses [11, 12]. These pathways are involved in a variety of developmental processes in yeasts and filamentous fungi $[12,13]$. The signaling model in yeast, Saccharomyces cerevisiae involving the Ste11-Ste7-Fus3/Kss1 cascade, has been characterized for pheromone responses and filamentous growth pathways [14]. In several phytopathogenic filamentous fungi, MAPK genes have been frequently annotated as virulence factors, such as Pmk1 in Magnaporthe oryzae [15-17], Cmk1 in C. orbicular [18], Kpp2 (Ubc3) in Ustilago maydis [19, 20], and Bmp1 in Botrytis cinerea [21]. The results of previous studies indicate that there are some differences in this signaling system between fungal plant pathogens and yeasts. In S. cerevisiae, certain protein kinases act in more than one pathway (e.g., the MEK Ste7 and MEKK Stell participate in two and three pathways, resp.); however, the Ste11-Ste7-Kss1 cascade is unique to pathogenesis in plant-pathogenic fungi [12, 13]. With the exception of differences in signaling systems, it is suggested that there are significant differences in the input/output of this cascade, not only between yeasts and plant pathogens, but also among different pathogens $[15,18-$ 20]. The inputs and outputs of these cascades are probably dependent on the fungal species, which suggests that the components of the MAPK cascades should be separately characterized for individual fungal plant pathogens.

The Stell-type MEKK and Ste7-type MEK are two important upstream kinases of the Fus3/Kss1-type MAPK cascade which has been considered a master regulator of pathogenesis in plant pathogens $[22,23]$. In previous work, the Ste7 homologues in many pathogens were found to be essential for appressorial formation in pathogenesis [24-28]. In this study, we identified and characterized ChSte7 encoding a MAPKK orthologue of the yeast Ste7 in C. higginsianum. Deletion of ChSte7 resulted in significant reduction in vegetative growth and loss of ability to form appressoria. Most interestingly, wounding inoculation assays and microscopic observations indicated that the ChSte7 deletion mutants were also defective in their invasive growth inside the host plant tissues. Otherwise, ChSte7 was highly expressed in the postinvasive growth phase. All these data support the involvement of ChSte7 in regulation of vegetative growth, appressorial formation, and postinvasive growth in host tissues.

\section{Materials and Methods}

2.1. Strains, Plasmids, and Plants. The wild-type strain IMI349061 of C. higginsianum (Table 1), originating from diseased tissues of $B$. campestris, was kindly provided by Professor Yangdou Wei from the University of Saskatchewan, Canada. Plasmids pMD18T-HYG with hph cassette and pNeo3300III with neocassette used for gene disruption and complementation vector construction [29] were stored at $-80^{\circ} \mathrm{C}$ in $20 \%$ glycerol (v/v) as bacterial suspensions.

Arabidopsis thaliana ecotype Col-0 was used in virulence assays. Arabidopsis seeds were sown on the surface of peat-based compost and placed in growth chamber with $16 / 8 \mathrm{~h}$ photoperiod and day and night temperatures of 22 and $18^{\circ} \mathrm{C}$, severally. Lighting provided a photosynthetic photon flux rate of $40 \mu \mathrm{mol} \mathrm{m} \mathrm{s}^{-2}(400-700 \mathrm{~nm})$, and the chamber was maintained at $65-80 \%$ relative humidity.

2.2. Disruption and Complementation of Target Gene ChSte7. To replace ChSte7, an 870 bp fragment of upstream flanking sequence and $950 \mathrm{bp}$ fragment of downstream flanking sequence of the gene were amplified, respectively, with primer pairs, ChSte7F1FP/ChSte7F1RP and ChSte7F2FP/ ChSte7F2RP (Table 2). PCR products of the upstream flanking sequence digested with HindIII/SalI and the downstream flanking sequence digested with $\mathrm{XbaI} / \mathrm{KpnI}$ were ligated into the corresponding restriction sites of vector pMD18T-HYG, resulting in the initial vector F1-HYG-F2. The vector F1-HYG-F2 was then digested with HindIII and KpnI and ligated with pNeo3300III to form the gene disruption vector pNeo3300IIIChSte7-Ko. The vector, pNeo3300IIIChSte7-Ko, was transformed into Agrobacterium tumefaciens EHA105 by electroporation, and then conidia of C. higginsianum wild-type strain were transformed with vector pNeo3300IIIChSte7-Ko based on the A. tumefaciensmediated transformation (ATMT) protocol described by $\mathrm{Li}$ et al. [30]. To obtain ChSte7 disruption mutants, transformants were grown on potato dextrose agar (PDA) supplemented with $50 \mu \mathrm{g} / \mathrm{mL}$ of hygromycin (Merck, Germany) and $500 \mu \mathrm{g} / \mathrm{mL}$ of cephalosporin (Amresco, USA) and then subcultured on PDA supplemented with $150 \mu \mathrm{g} / \mathrm{mL}$ antibiotic G418 (Amresco, USA). Gene disruption transformants were confirmed by PCR amplification with two pairs of primers, ChSte7-KF/ChSte7-KR and HphSP/HphAP (Table 2), and RT-PCR with primers ChSte7-KF and ChSte7-KR (Table 2).

To confirm that phenotypes of the ChSte7 disruption mutants were due to the targeted gene disruption, one disruption mutant $\Delta$ ChSte7-26 (Table 1) was complemented with a full length sequence of ChSte7. Since the upstream sequence of ChSte7 was not found in sequencing scaffolds of the C. higginsianum assembly, high-efficiency thermal asymmetric interlaced PCR (hiTAIL-PCR) was used to amplify the upstream sequence of ChSte7 (corresponding to the promoter region). For hiTAIL-PCR, genomic DNA was used as a template in successive reactions with nested RB-specific primers RB-0a, RB-1a, and RB-2a together with the degenerate primers LAD1-1, LAD1-2, LAD1-3, LAD14, and AC1 following thermal cycling settings for hiTAILPCR described by Liu and Chen [31]. The 3882 bp fragment including the $1728 \mathrm{bp}$ ORF of ChSte7, $1674 \mathrm{bp}$ upstream, and $480 \mathrm{bp}$ downstream was amplified from genomic DNA of the wild-type strain with primer pair Ste7comFP and Ste7comRP (Table 2) and cloned into the HindIII site of vector pCAMBIA3300III, generating the complementation plasmid pNeo3300IIIChSte7-Com. To obtain the ChSte7 complementation transformants, conidia of $\Delta$ ChSte7-26 were transformed with vector pNeo3300IIIChSte7-Com by the ATMT method. The complementation transformants were screened on PDA containing $150 \mu \mathrm{g} / \mathrm{mL}$ G418, and gene fragments were detected by PCR and RT-PCR analyses. 
TABLE 1: Strains used in this study.

\begin{tabular}{lcc}
\hline Strain & Description & Reference \\
\hline Ch-1 & Colletotrichum higginsianum IMI349063 & {$[4]$} \\
$\Delta$ ChSte7-26 & ChSte7 disruption mutant from Ch-1 & This study \\
$\Delta$ ChSte7-48 & ChSte7 disruption mutant from Ch-1 & This study \\
C $\Delta$ ChSte7-26-20 & ChSte7 complementation strain from $\Delta$ ChSte7-26 & This study \\
EHA105 & Agrobacterium tumefaciens competent cell & {$[8]$} \\
DH5 $\alpha$ & Escherichia coli competent cell & {$[8]$} \\
\hline
\end{tabular}

TABLE 2: Primers used in this study.

\begin{tabular}{ll}
\hline Primer & Sequence $\left(5^{\prime}\right.$ to $\left.{ }^{\prime}\right)$ \\
\hline ChSte7FP & ATGGCCGATCCTTTTGCGC \\
ChSte7RP & CTAGTTGGAGGTACCATTGTACACATCG \\
ChSte7F1Fp & CCCAAGCTTGGATACTGTCCATCACTTCATCGCC \\
ChSte7F1Rp & ACGCGTCGACCCATGCATGATCTGGAGCTCACG \\
ChSte7F2Fp & GCTCTAGAAAAGTGATGAACGCTTGGGCA \\
ChSte7F2Rp & GGGGTACCGACCCTCCCGTCTCCTTCG \\
ChSte7-KF & TCGGGTAAGTTTGGCTTTGTTTCA \\
ChSte7-KR & CTAGTTGGAGGTACCATTGTACACATCG \\
HphSp & TTCTGCGGGCGATTTGTG \\
HphAp & AGCGTCTCCGACCTGATG \\
ChSte7comFP & CCCAAGCTTGCTTAACCATCGGCAACTTCATG \\
ChSte7comRP & CCCAAGCTTTAGGATAGGAGGCCCTTCCCTGACT \\
TubulinS & AGAAAGCCTTGCGACGGAACA \\
TubulinA & CCTCCAGGGTTTCCAGATTA \\
qRT-STE7F & CAAGAAAGAGATGCGTAAG \\
qRT-STE7R & GCCGTAGAAGTTGACAATA \\
qRT-tubulinF & ATGCAGATGTCGTAGAGA \\
qRT-tubulinR & ACTGTTGTTGAGCCTTAC \\
\hline
\end{tabular}

Restriction enzyme cutting sites are underlined.

2.3. Phenotypic Analysis. Mycelia of the wild-type strain and mutants were inoculated onto PDA plates and cultured in darkness for 7 days at $25^{\circ} \mathrm{C}$ for growth rate and conidiation testing. Mycelia were harvested by suction filtration from 7 -day-old cultures grown in $100 \mathrm{~mL}$ potato dextrose broth (PDB) at $25^{\circ} \mathrm{C}$ with shaking at $150 \mathrm{rpm}$, dried at $60^{\circ} \mathrm{C}$, and weighed. Hyphae picked from edge of the colony on PDA were examined by light microscopy (Nikon, Tokyo, Japan). Conidia were harvested with sterile distilled water and passed through four layers of lens paper to remove debris and mycelia. The conidial suspension was adjusted to a concentration of $1 \times 10^{6}$ spores $/ \mathrm{mL}$ with sterile deionized water and suspension droplets $(10 \mu \mathrm{L})$ were spotted on microscope plastic coverslips (Thermo Fisher Scientific, MA, USA) placed in $9 \mathrm{~cm}$ diameter petri dishes, and conidial germination and appressorial formation were examined by light microscopy after $12 \mathrm{~h}$.

2.4. Pathogenicity Assay and Infection Observation. Conidial suspensions at the concentration of $1 \times 10^{6}$ spores $/ \mathrm{mL}$ were prepared as stated above and used for plant inoculation. Intact plants of Arabidopsis were used to assess the virulence of the disruption and complementation transformants of ChSte7. Conidial suspensions were sprayed onto the upper and lower surfaces of Arabidopsis leaves from 4- to 5-weekold plants. After sealing the plants inside plastic propagators lined with wet tissue paper to provide high humidity, inoculated plants were incubated at $25^{\circ} \mathrm{C}$ in a controlled environment chamber (18 h photoperiod). Lesion formation was examined at 5 days after inoculation (dpi).

To observe infection structures of wild-type strain and mutants, Arabidopsis leaves from 4- to 5-week-old plants were spotted with $10 \mu \mathrm{L}$ droplets of the prepared conidial suspension on either side of each midvein. Inoculated leaves were incubated in complete darkness at $25^{\circ} \mathrm{C}$. Inoculated leaf tissues collected after 4 days of incubation were cleared in a solution of methanol: chloroform: glacial acetic acid $(6: 3: 1)$, then rehydrated and stained with $1 \%$ trypan blue in glycerol, and viewed by light microscopy.

To assess the ability of the ChSte7 disruption mutants to grow invasively inside the host plant tissues independent of penetration, conidial suspensions were also spotted on wounded site of the Arabidopsis leaves. Wounding experiments were carried out by pricking the detached leaves with a fine sterile needle prior to inoculation and placing 
conidial suspensions directly on the wound sites. Lesion formation was examined at $4 \mathrm{dpi}$ and inoculated leaf tissues were cleared, rehydrated and stained, and finally viewed by light microscopy.

2.5. DNA/RNA Manipulation, RT-PCR, and qRT-PCR Analysis. Total genomic DNA (gDNA) was isolated from C. higginsianum wild-type strain with CTAB following Sambrook et al. [32]. Hyphae harvested from PDB, conidia obtained from PDA plates, and Arabidopsis leaves sprayed with conidial suspension at concentration of $1 \times 10^{6}$ spores $/ \mathrm{mL}$ at 5,20 , 40,65 , and $90 \mathrm{~h}$ after incubation (hpi) were collected, flashfrozen in liquid nitrogen, and stored at $-80^{\circ} \mathrm{C}$ until required. RNA isolation was carried out using TRIzol ${ }^{\circledR}$ Plus RNA Purification Kit (Invitrogen, Carlsbad, USA), and potential DNA contamination was removed by DNase I treatment (RNase Free) (Takara, Dalian, China) following manufacturer's instructions. First-strand cDNA was synthesized by using Revert Aid first-strand cDNA synthesis kit (Fermentas, St. Leon-Rot, Germany) following the manufacturer's instructions. Expressions of ChSte7 in disruption mutants and the complementation strain were examined by RTPCR, and a $1208 \mathrm{bp}$ fragment was amplified with genespecific primers ChSte7-KF and ChSte7-KR (Table 2). The C. higginsianum $\beta$-tubulin sequence amplified with primers TubulinS and TubulinA (Table 2) was used as the reference gene. PCR conditions were 25 cycles of $94^{\circ} \mathrm{C}$ for $30 \mathrm{~s}, 55^{\circ} \mathrm{C}$ for $30 \mathrm{~s}$, and $72^{\circ} \mathrm{C}$ for $1 \mathrm{~min}$ and with a final extension at $72^{\circ} \mathrm{C}$ for $5 \mathrm{~min}$. Expression of ChSte7 at different development stages of the fungus in vitro or in planta was analyzed by qRT-PCR with ChSte7 gene-specific primers qRT-STE7F/qRT-STE7R (Table 2). The C. higginsianum $\beta$-tubulin as the reference gene was amplified with primers qRT-tubulinF and qRT-tubulinR (Table 2). PCR conditions were 50 cycles of $95^{\circ} \mathrm{C}$ for $15 \mathrm{~s}, 55^{\circ} \mathrm{C}$ for $20 \mathrm{~s}$, and $72^{\circ} \mathrm{C}$ for $20 \mathrm{~s}$ and with a final extension from $65^{\circ} \mathrm{C}$ to $95^{\circ} \mathrm{C}\left(0.5^{\circ} \mathrm{C} / 5 \mathrm{~s}\right)$. PCR reactions were run on a PTC200 DNA Engine Peltier Thermal Cycler (Bio-Rad, Hercules, USA).

2.6. Bioinformatics. The full sequence of ChSte7 was downloaded from the C. higginsianum genome database (http:// www.broadinstitute.org/annotation/genome/colletotrichum _ group/MultiHome.html). To confirm sequence validity, the primers ChSte7FP and ChSte7 RP (Table 2) were designed and used for the amplification of the ChSte7 gene. All primers used in this work were designed with primer premier 5.0 (http://www.premierbiosoft.com/primerdesign/). Open reading frames were further analyzed using the gene prediction program FGENESH (Softberry Inc., Mount Kisco, NY, USA). Protein domain and motif predictions were performed with SMART software (http://smart.embl-heidelberg.de/). The Ste7 protein sequences from different organisms were obtained from the GenBank database, using the BLAST algorithm. Sequence alignments were performed using the Clustal X (version 2.0, http://www.clustal.org/ clustal2/), and the phylogenetic tree was generated by the Mega software (version 5.0, http://www.megasoftware.net/ index.php).
2.7. Statistical Analysis. The data of all quantitative assays were analyzed with DPS statistical analysis software (version 3.01, China Agric. Press, Beijing, China), using analysis of variance and the test of Least Significant Difference (LSD) at $P=0.05$.

\section{Results}

3.1. Identification and Characterization of ChSte7. The protein sequence of Ste7 from S. cerevisiae was used as the query to blast (BLASTp) against available C. higginsianum genome. We identified a locus CH063_02455 named as ChSte7 which encodes the Ste7 homologue and is predicted to encode a 522 -amino-acid protein that shares $44 \%$ identity with Ste7 in S. cerevisiae. Sequence analysis with SMART revealed that $\mathrm{ChSte} 7$ contained a $\mathrm{S}_{-} \mathrm{TK}$ c conserved domain (serine/threonine protein kinases, catalytic domain) (Figure 1(a)). Phylogenetic analysis of ChSte7 to other Ste7 proteins revealed that ChSte7 from C. higginsianum was most similar to Ste7 proteins of C. gloeosporioides and $C$. orbiculare and most distant from those of Bipolaris maydis and S. cerevisiae (with identities still close to or above 44\%) (Figure 1(b)). This result indicates that Ste7 proteins are conserved in fungi.

3.2. ChSte7 Is Highly Expressed during Invasive Growth. To gain insight into the functions of ChSte7, we first examined the gene expression profile at different stages of C. higginsianum using qRT-PCR. In comparison to the conidiation stage, the expression levels of ChSte7 were significantly increased in vegetative and invasive growth stages (5 to 90 hpi) (Figure 2). The expression of ChSte7 was highest in the vegetative stage while no expression was found in the conidiation stage. Lower expressions were detected during the early stages of infection at 5-40 hpi. However, the expression of ChSte7 increased significantly during late infection until 90 hpi. These observations suggest that ChSte7 is highly expressed in the late infection and may play a key role during necrotroph in C. higginsianum.

3.3. Targeted Disruption and Complementation of ChSte7. A gene disruption vector, pNeo3300IIIChSte7-Ko (Figure 3(a)), containing hygromycin B phosphotransferase (hph) gene and both $5^{\prime}$ and $3^{\prime}$ flanking regions of ChSte7, was constructed and then transformed into the wild-type strain. The transformants were first selected on hygromycin-containing media and then selected on G418-containing media to avoid random insertion. Fifty candidate disruption transformants without resistance to G418 among 348 hygromycin-resistant transformants were obtained. Two candidate disruption transformants $\Delta$ ChSte7-26 and $\Delta$ ChSte7-48 were found lacking the 1208 bp ChSte7 fragment compared to the wild-type strain after PCR amplification with STE7SP/STE7AP (Table 2), but an 887-bp hph fragment was obtained by PCR amplification with hphF/hphR (Table 2) in the two candidate transformants (Figure 3(b)). Null mutation of the ChSte7 gene was further confirmed by RT-PCR analysis, since the ChSte7 transcript was not detected in these two targeted disruption transformants (Figure 3(c)). These results demonstrated that the 


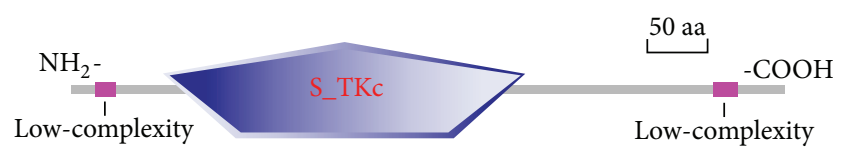

(a)

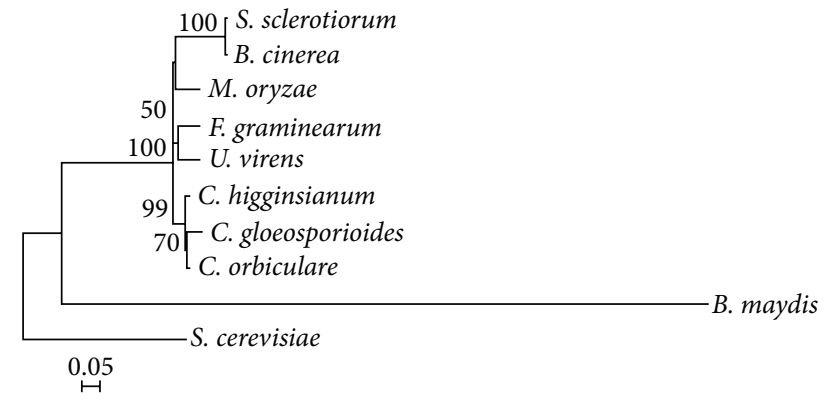

(b)

FIGURE 1: Functional domain identification and phylogenetic tree. (a) A conserved S_TKc domain (serine/threonine protein kinases, catalytic domain) and two low-complexity regions in ChSte7 were predicted using the SMART website. (b) Sequence alignments were performed using Clustal X 2.0 program and the calculated phylogenetic tree was viewed using Mega 5.0 program. Neighborjoining tree was constructed with 1000 bootstrap replicates of phylogenetic relationships between Ste7 homologues in fungi. All 10 protein sequences of the Ste7 homologues were downloaded from the NCBI database and the accession numbers of Ste7 homologues are shown as follows: S. sclerotiorum (Sclerotinia sclerotiorum XP_001588345.1), B. cinerea (Botrytis cinerea XP_001557712.1), M. oryzae (Magnaporthe oryzae ELQ32975.1), F. graminearum (Fusarium graminearum XP_011318809.1), U. virens (Ustilaginoidea virens KDB12657.1), C. higginsianum (Colletotrichum higginsianum CCF40893.1), C. gloeosporioides (Colletotrichum gloeosporioides AAD55385.1), C. orbiculare (Colletotrichum orbiculare ENH81835.1), B. maydis (Bipolaris maydis EMD86379.1), and S. cerevisiae (Saccharomyces cerevisiae CAA98732.1).

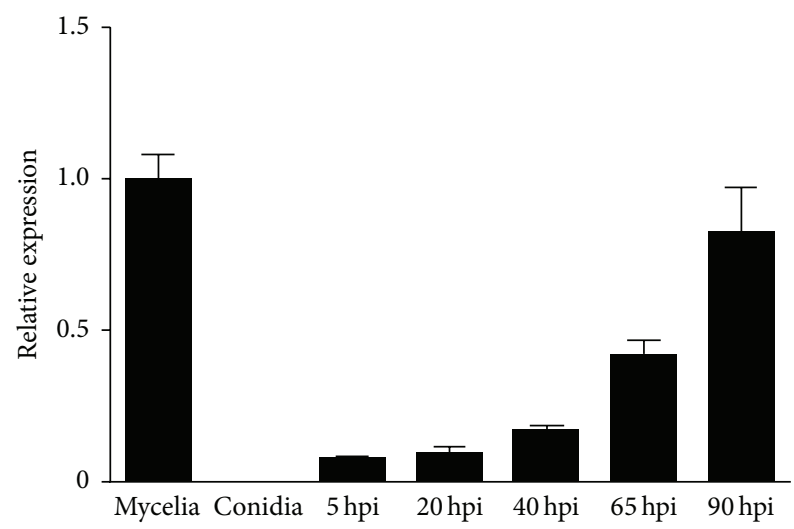

FIGURE 2: Expression profiles of ChSte7 assayed by qRT-PCR. RNA was extracted from mycelia and conidia, as well as infected Arabidopsis seedlings at different times of inoculation $(5,20,40$, 65 , and $90 \mathrm{hpi}) . \beta$-tubulin gene was used as an internal control. Relative abundance of ChSte7 transcripts during infectious growth was normalized by comparing with vegetative growth in potato dextrose broth (relative transcript level $=1$ ). Three independent biological experiments with three replicates in each treatment were performed.
ChSte7 gene was deleted in the ChSte7 disruption transformants $\Delta$ ChSte7-26 and $\Delta$ ChSte7-48. To investigate whether altered growth phenotypes and the loss of virulence in ChSte7 disruption transformants could be restored by reintroduction of a wild-type copy of ChSte7, we transformed $\Delta$ ChSte7-26 with plasmid pNeo3300IIIChSte7-Com. Subsequently, complementation transformant $\mathrm{C} \Delta$ ChSte7-26-20 was confirmed by PCR and RT-PCR analysis (Figures 3(b) and 3(c)) and chosen for further phenotype analysis.

3.4. ChSte7 Plays a Crucial Role in Vegetative Growth and Colony Morphology. To explore the role of ChSte7 in vegetative growth and colony morphology, the $\Delta$ ChSte 7 mutants and the complementation transformant together with the wild-type strain were cultured on PDA plates for 7 days. The $\Delta$ ChSte7 mutants showed a significantly reduced growth rate and biomass while conidial production was consistent with the wild-type and complementation strain (Table 3). The growth rate and biomass of the $\Delta$ ChSte 7 mutants were reduced to approximately $55.8-58.1 \%$ and $31.6-38.8 \%$, respectively, compared with those of the wild-type strain. The $\Delta$ ChSte7 mutants showed irregular-shape colonies, as well as increased aerial hyphae (Figure 4(a)). Moreover, the $\Delta C h S t e 7$ mutants produced wavy and twisted hyphae with increased branching (Figure 4(b)). These results suggest that ChSte7 plays an important role in hyphal growth and morphology.

3.5. ChSte7 Is Essential for Appressorial Formation and Pathogenicity in C. higginsianum. In order to investigate whether ChSte7 is essential for pathogenicity, we first tested the ability to form appressoria by placing droplets of conidial suspensions on artificial hydrophobic surface. The wildtype strain started to form many appressoria by $12 \mathrm{~h}$ after inoculation. In contrast, the $\Delta$ ChSte 7 mutants germinated poorly (Table 3 ) and did not form any appressoria, even after $24 \mathrm{~h}$ (Figure 4(c)). Moreover, $\Delta$ ChSte7 mutants often formed long germ tubes. The ChSte7 complementation strain CAChSte7-26-20 regained the ability to form normal appressoria (Figure 4(c)).

To test the pathogenicity of mutants, conidial suspensions of all strains were inoculated onto nonwounded Arabidopsis leaves. The $\Delta$ ChSte 7 mutants were nonpathogenic while the wild-type and C $\Delta$ ChSte7-26-20 strain were virulent and formed typical necrotic lesions on leaves (Figure 5(a)).

To verify whether the loss of virulence of the $\Delta C h S t e 7$ mutants was attributable to the defect in appressorial formation, we investigated the formation of different infection structures by $\Delta$ ChSte 7 mutants on Arabidopsis leaves. At $4 \mathrm{dpi}$, high frequencies of appressorial formation and penetration on the surface of Arabidopsis leaves were found in both the wild-type and C $\Delta$ ChSte7-26-20 strain (above 90\%; Figures 5(b) and 5(c)). The $\Delta$ ChSte 7 mutants germinated but did not form appressoria on the plant surface, and also no invasive hyphae were observed in the epidermal cells (Figures 5(b) and 5(c)), indicating that loss of pathogenicity of the $\Delta$ ChSte7 mutants was caused, at least in part, by defects in appressorial formation. These observations showed that ChSte7 is required in the early stage of the infectious process, 


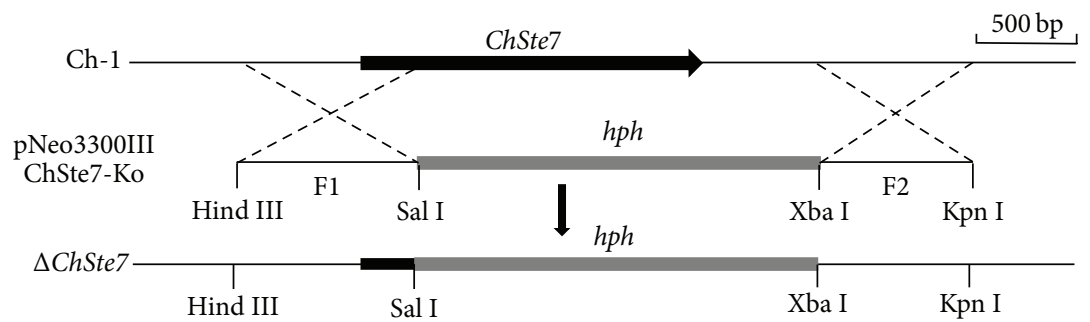

(a)

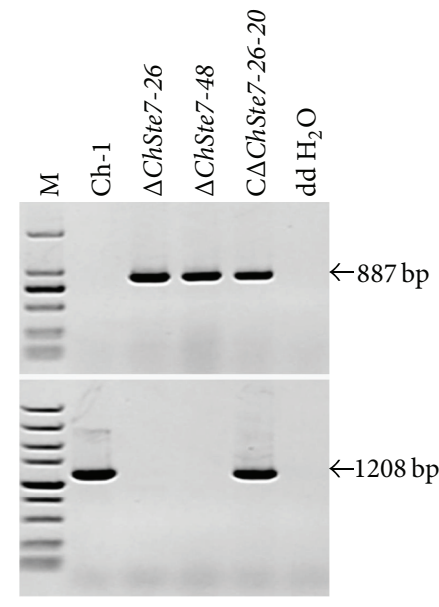

(b)

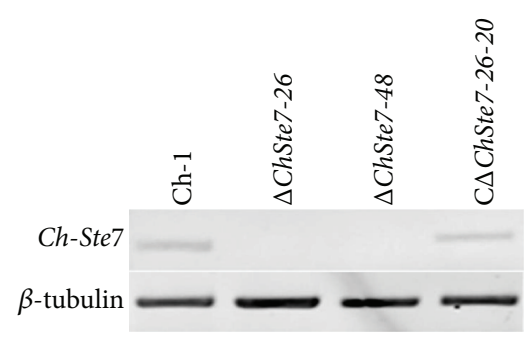

(c)

Figure 3: Targeted disruption and complementation of ChSte7 gene. (a) ChSte7 locus and gene deletion vector. (b) PCR analysis of wild-type strain (Ch-1), ChSte7 disruption mutants ( $\Delta$ ChSte7-26 and $\Delta$ ChSte7-48), and complementation strain (CDChSte7-26-20). Markers (M) in the top and bottom images are DL2000 and DL5000, respectively. The band of $877 \mathrm{bp}$ in hph gene was amplified in the ChSte7 disruption mutants and complementation strain while a 1208 bp fragment in ChSte7 gene was obtained in the wild-type and complementation strains. (c) RT-PCR analysis of wild-type strain, ChSte7 disruption mutants, and complementation strain.

TABLE 3: Growth rate, biomass, conidiation, and conidial germination of the ChSte7 disruption mutants and complementation strain of $C$. higginsianum.

\begin{tabular}{lcccc}
\hline Strain & Growth rate $(\mathrm{mm} / \mathrm{d})$ & Mycelial dry weight $(\mathrm{mg} / \mathrm{mL})$ & Conidiation $\left(10^{6} /\right.$ plate $)$ & Germination rate $(\%)$ \\
\hline Ch-1 & $4.3 \pm 0.2^{\mathrm{a}}$ & $2.9 \pm 0.1^{\mathrm{a}}$ & $28.0 \pm 2.0^{\mathrm{a}}$ & $75.5 \pm 6.9^{\mathrm{a}}$ \\
$\Delta$ ChSte7-26 & $2.4 \pm 0.1^{\mathrm{b}}$ & $1.1 \pm 0.2^{\mathrm{b}}$ & $26.7 \pm 1.5^{\mathrm{a}}$ & $6.2 \pm 0.6^{\mathrm{b}}$ \\
$\Delta$ ChSte7-48 & $2.5 \pm 0.1^{\mathrm{b}}$ & $0.9 \pm 0.2^{\mathrm{b}}$ & $27.0 \pm 0.7^{\mathrm{a}}$ & $7.5 \pm 2.0^{\mathrm{b}}$ \\
C $\Delta$ ChSte7-26-20 & $4.2 \pm 0.1^{\mathrm{a}}$ & $2.9 \pm 0.2^{\mathrm{a}}$ & $24.7 \pm 0.6^{\mathrm{a}}$ & $76.5 \pm 3.3^{\mathrm{a}}$ \\
\hline
\end{tabular}

Numbers indicated by the same letter in the same column are not significantly different at $P=0.05$ in a test of LSD.

which corresponds with the results of appressorial formation experiments.

3.6. ChSte7 Disruption Mutants Are Avirulent on Wounded Leaf Tissues. To assess the ability of the $\Delta$ ChSte 7 mutants to grow invasively inside the host plant tissues independent of penetration, conidia of the $\Delta$ ChSte 7 mutants were directly inoculated on the wound sites of Arabidopsis leaves. At 4 dpi, the $\Delta$ ChSte7 mutants could not form lesions on wounded leaf tissues while the wild-type and the CAChSte7-26-20 strain caused dark necrotic lesions on inoculation sites (Figure 6(a)). Microscopic observation showed that conidia of the $\Delta$ ChSte7 mutants never formed appressoria on Arabidopsis leaves, and germinating conidia could not form invasive hyphae to enter into the wound sites but did produce aerial hyphae beyond or around wound sites (Figures 6(b) and 6(c)). The results indicated that $\Delta$ ChSte 7 mutants lost the ability for invasive growth in the host tissues. Therefore, we concluded that the loss of virulence in $\Delta C h S t e 7$ mutants was attributable to the defects in both appressorial formation and invasive growth.

\section{Discussion}

The MAPK cascade is one of the most important signaling systems in the regulation of morphogenesis and stress responses. Most filamentous fungi including C. higginsianum possess three conserved MAPK cascades. One of the cascades, the Stell-Ste7-Fus3/Kss1-type cascade, has been considered as a master regulator of pathogenesis in 


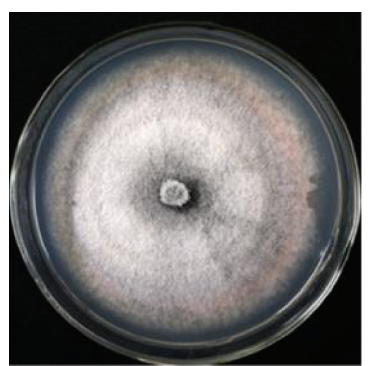

Ch-1

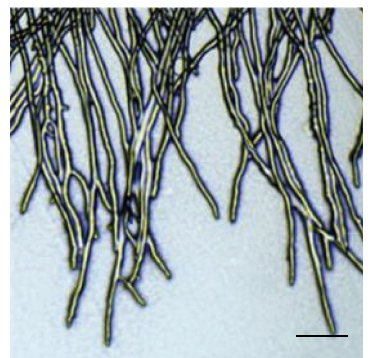

Ch-1

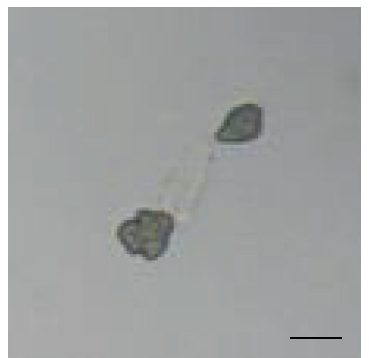

Ch-1

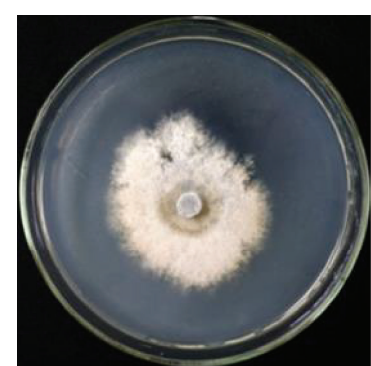

$\Delta$ ChSte7-26

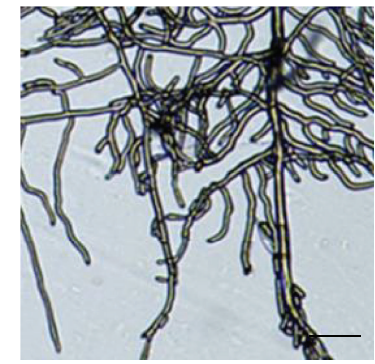

$\Delta$ ChSte7-26

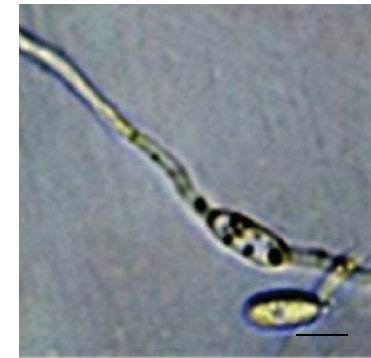

$\Delta$ ChSte7-26

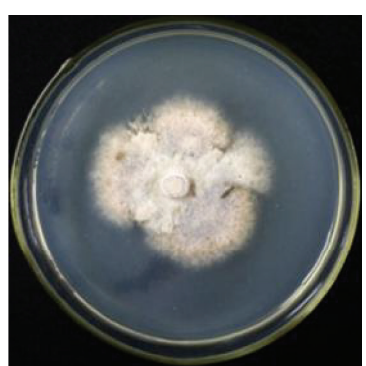

$\Delta$ ChSte $7-48$

(a)

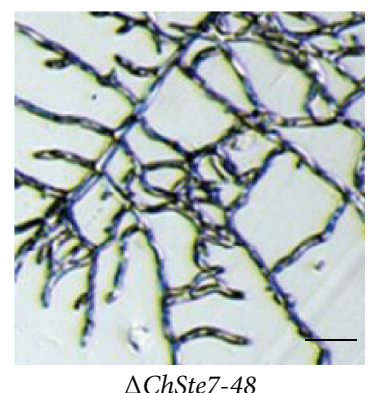

(b)

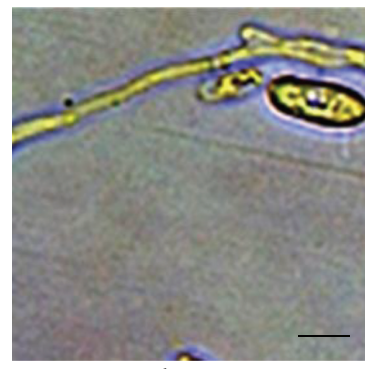

$\Delta$ ChSte7-48

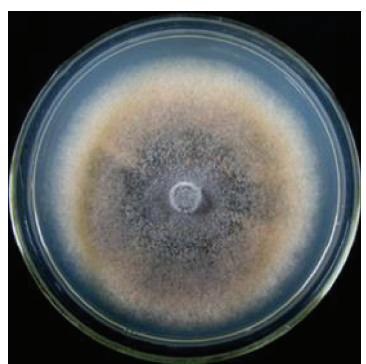

CAChSte7-26-20

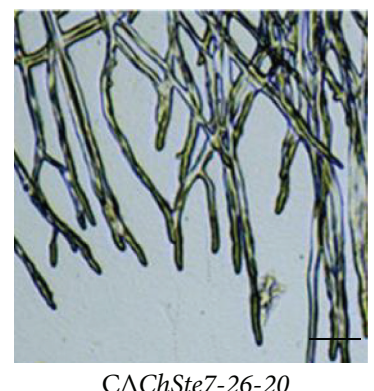

C $\Delta$ ChSte7-26-20

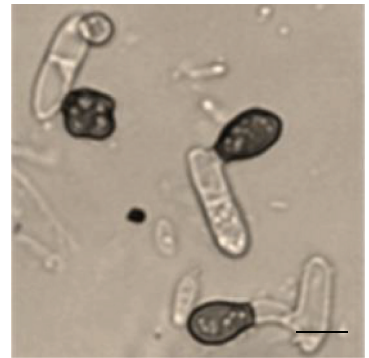

CAChSte7-26-20

(c)

Figure 4: Mycelial growth and appressorial formation of ChSte7 disruption mutants and complementation strain. (a) The ChSte7 disruption caused abnormal colony. Wild-type strain Ch-1, ChSte7 disruption mutants $\Delta$ ChSte7-26 and $\Delta$ ChSte7-48, and complementation strain C $\Delta$ ChSte7-26-20 were grown on PDA plates for 7 days. (b) Increased furcation of mycelial tips and twisted hyphae were observed for the $\Delta$ ChSte 7 mutants. Hyphae of Ch-1, ChSte7 disruption mutants, and complementation strain picked from the edge of the colonies were examined by light microscopy. Scale bar $=10 \mu \mathrm{m}$. (c) Appressorial formation was altered in the ChSte7 disruption mutants. Conidial suspensions of Ch-1, ChSte7 disruption mutants, and complementation strain in distilled water were incubated on hydrophobic surface at $25^{\circ} \mathrm{C}$ for $24 \mathrm{~h}$. Scale bar $=5 \mu \mathrm{m}$.

plant pathogens $[13,22,23,33]$. The similar phenotypes of mutants in this cascade were observed in previous studies for M. oryzae $[15,16,27,28]$, B. cinerea $[21,34]$, C. lagenarium $[18,35], U$. maydis $[19,20]$, and other plant pathogens. These findings implied that Ste7-type MEK was an essential component of the Stell-Ste7-Fus3/Kss1-type cascade. The Fus3/Kss1type cascade has been well characterized in some model species of fungal plant pathogens; however, two upstream kinases, Stell-type MEKK and Ste7-type MEK, have only been characterized in a few systems. In this study, we identified and characterized Ste7-type MEK in C. higginsianum, in order to elucidate the functional roles of Ste7, using disruption mutant strains. Consequently, we found Ste7-type MEK in C. higginsianum to be involved in various stages of development and morphogenesis in lifecycles, such as hyphae development, appressorial formation, and postinvasive growth. This is the first description of roles of Ste7-type MEK in the model phytopathogen C. higginsianum.

Homologues of Ste7 MEK are involved in appressorial formation, an important infection-related morphogenetic process, in M. oryzae [27, 28], Colletotrichum spp. [18, 25, 35], $B$. cinerea $[21,34]$, and $U$. maydis $[19,20,26]$ as well as B. maydis [24, 36, 37]. We suggest that the Fus3/Kss1-type MAPK cascade has highly conserved roles in appressorial formation among plant pathogens. If the involvement of ChSte7 was confined to the initial penetration into the host, then the disruption mutant should be able to infect a host with a mechanically breached outer surface. However, ChSte7 


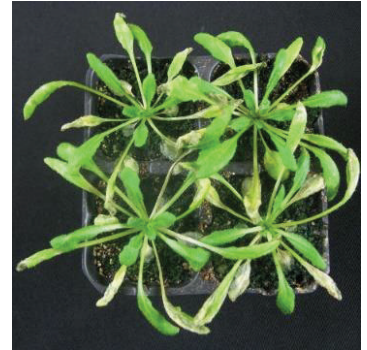

Ch-1

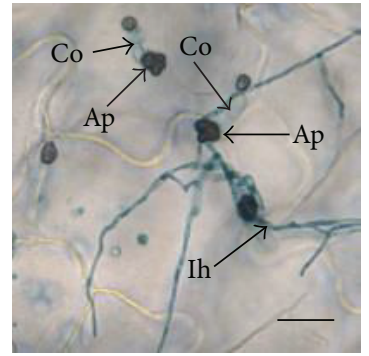

Ch-1

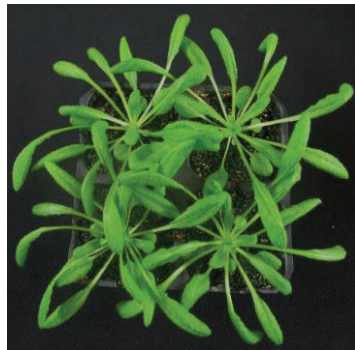

$\Delta$ ChSte7-26

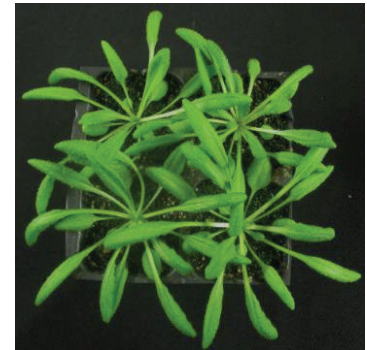

$\Delta$ ChSte7-48

(a)

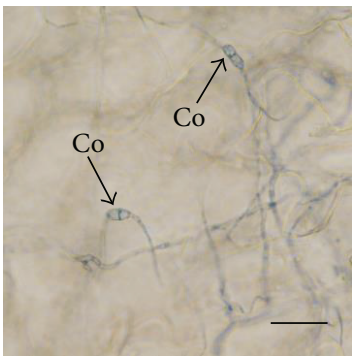

$\Delta$ ChSte7-26

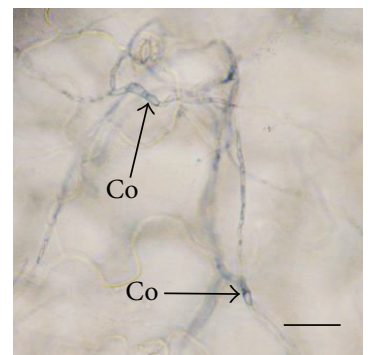

$\Delta$ ChSte7-48

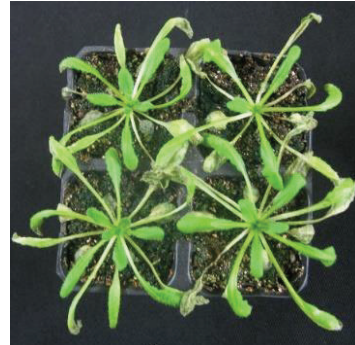

CAChSte7-26-20

(b)

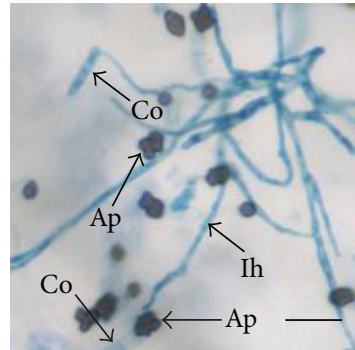

CAChSte7-26-20

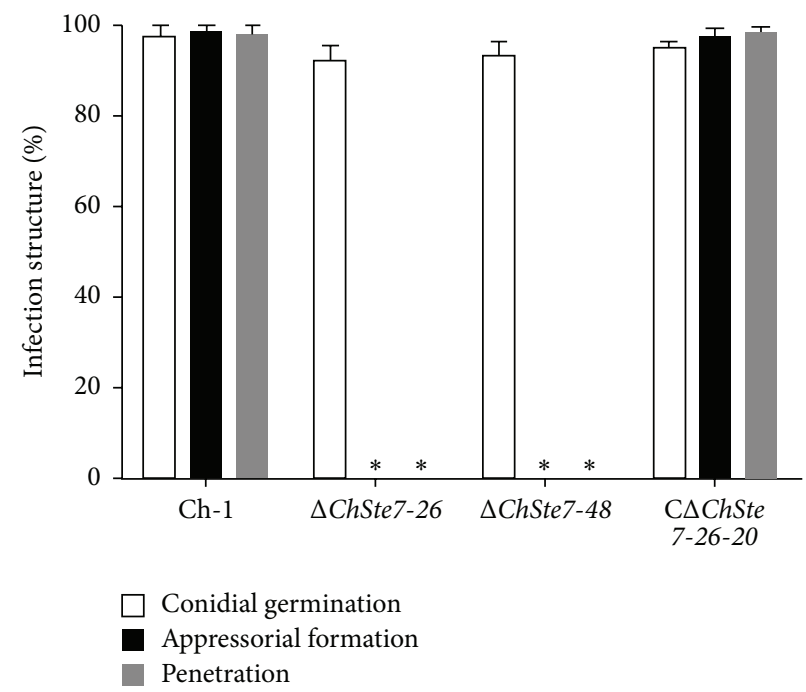

(c)

Figure 5: Deficiency in pathogenicity and appressorial formation of ChSte7 disruption mutants on leaves of Arabidopsis plants. (a) The ChSte7 disruption attenuated pathogenicity on Arabidopsis leaves. Conidia suspensions of wild-type strain Ch-1, ChSte7 disruption mutants $\Delta$ ChSte7-26 and $\Delta$ ChSte7-48, and complementation strain C $\Delta$ ChSte7-26-20 were sprayed onto the Arabidopsis leaves incubated at $25^{\circ} \mathrm{C}$ for 5 days. (b) Conidial suspensions of wild-type strain, ChSte7 disruption mutants, and complementation strain were inoculated onto the surfaces of Arabidopsis leaves and incubated for 4 days. The appressoria of the ChSte7 disruption mutants were not formed, whereas the appressoria of C $\Delta$ ChSte7-26-20 and Ch-1 penetrated epidermal cells and produced abundant invasive hyphae. Ap, appressoria; Co, conidia; Ih, invasive hyphae. Scale bar $=20 \mu \mathrm{m}$. (c) Development of infection structures by wild-type strain, ChSte7 disruption mutants, and complementation strain on Arabidopsis leaves at 4 dpi. Ratings for infection structures were given as a percentage of the preceding structure. In each experiment, at least 300 appressoria per strain were examined. Means and standard deviations were calculated from three repeated experiments. Asterisks indicate values significantly different from the wild-type (LSD, $P<0.05$ ), and standard error bars are shown.

disruption mutants of $C$. higginsianum were unable to form lesions on wounded Arabidopsis leaves. Moreover, ChSte7 was highly expressed in the late infection but not in early infection stage. We suggest that Ste7-type MEK might be a crucial factor in pathogenicity of other necrotrophic fungi.
In this study, the results showed that the Ste7-type MEK was not involved in conidiation but did affect conidial germination in C. higginsianum. The ChSte7 disruption mutants produced as many conidia as the wild-type strain, but the conidia of ChSte7 disruption mutants germinated poorly 


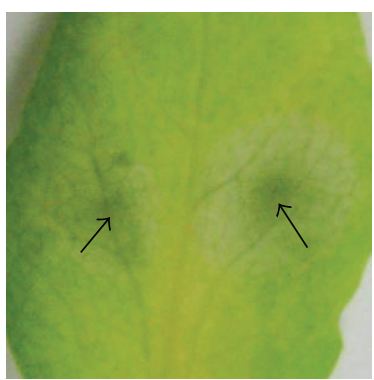

Ch-1

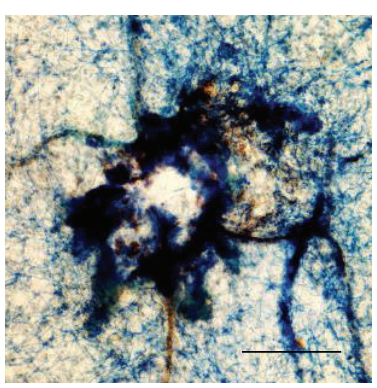

Ch-1

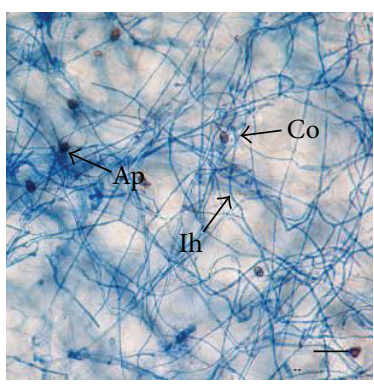

Ch-1

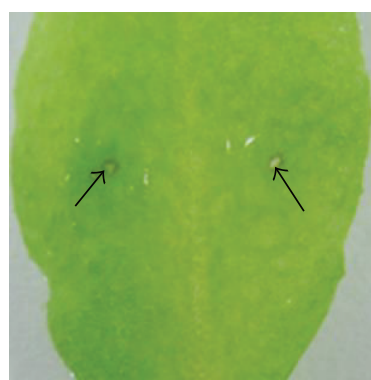

$\Delta$ ChSte7-26

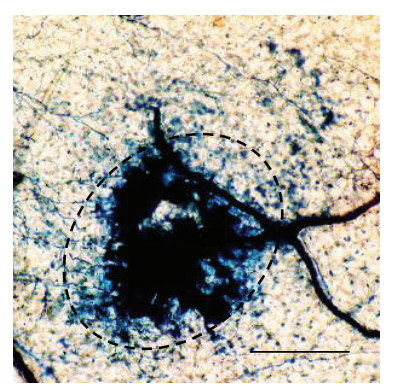

$\Delta$ ChSte7-26

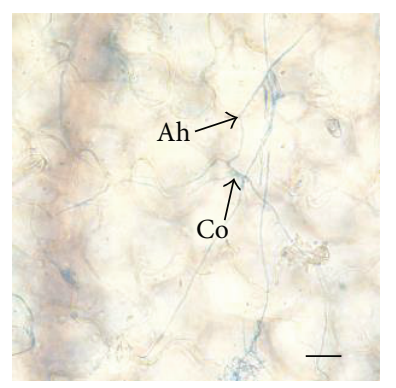

$\Delta$ ChSte7-26

(a)

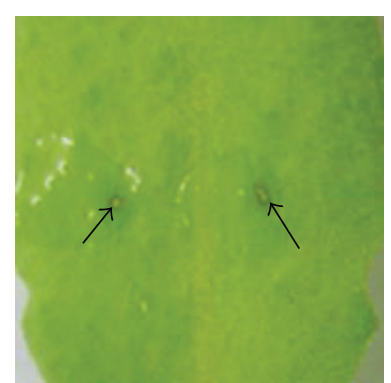

$\Delta$ ChSte7-48

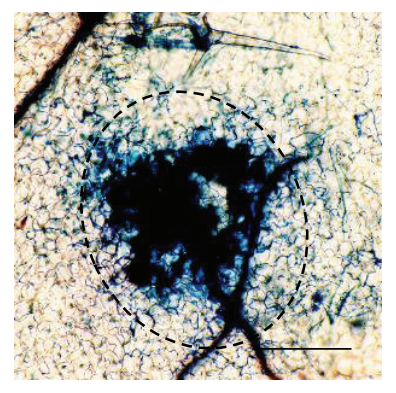

$\Delta$ ChSte7-48

(b)

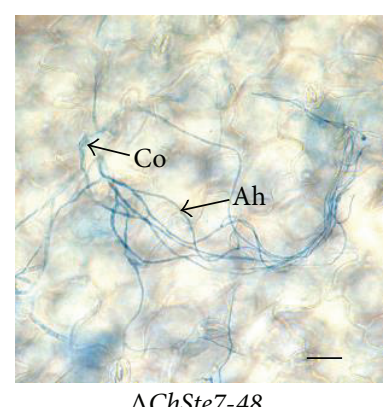

$\Delta$ ChSte7-48

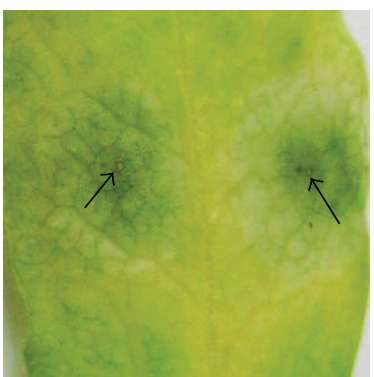

CAChSte7-26-20

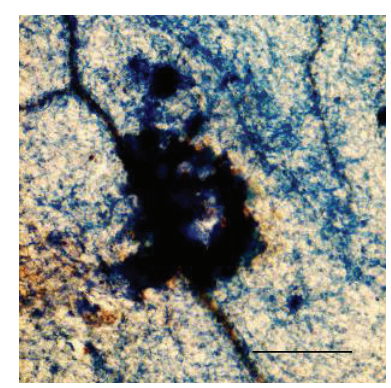

C $\Delta$ ChSte7-26-20

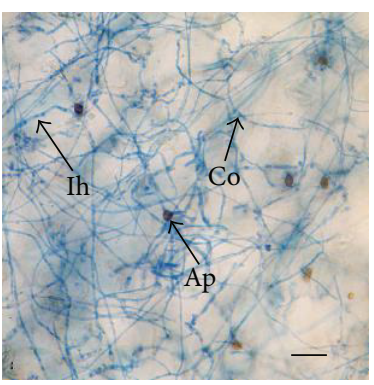

CAChSte7-26-20

(c)

FIGURE 6: Loss of the ability for invasive growth of ChSte7 disruption mutants in leaves of Arabidopsis. (a) Pathogenicity assays were performed on wounded leaves of Arabidopsis plants using conidia suspensions of wild-type strain Ch-1, ChSte7 disruption mutants $\Delta C h S t e 7-26$ and $\Delta$ ChSte7-48, and complementation strain C $\Delta$ ChSte7-26-20. At 4 dpi, the ChSte7 disruption mutants caused no symptoms on wounded tissues, while wild-type and complementation strain caused water-soaked lesions on wounded leaf tissues. Arrows indicate wounded sites on leaves. (b) Leaf tissues from wound sites were viewed by light microscopy. Hyphae from germinating conidia of the ChSte7 disruption mutants grew above the epithelial cells of Arabidopsis leaves and could not enter into the wound sites. Scale bar $=100 \mu \mathrm{m}$. (c) Near the wound sites, appressoria of the ChSte7 disruption mutants were not formed on leaves, and germinating conidia could not form invasive hyphae to enter into the wound sites but produce aerial hyphae beyond or around wound sites. Ah, aerial hyphae; Ap, appressoria; Co, conidia; Ih, invasive hyphae. Scale bar $=10 \mu \mathrm{m}$.

(6\%) on plastic coverslips. However, the germination rate of conidia of ChSte7 disruption mutants was more than $92 \%$ at 5 dpi on Arabidopsis leaves. We speculate that the inhibition of conidial germination in ChSte7 disruption mutants might be overcome on leaf surfaces by host signals and nutrients. Previous studies indicated that the Fus3/Kss1-type MAPK cascade regulated conidiation in $M$. oryzae $[15,27]$ and other Colletotrichum spp. $[18,25,35]$ as well as B. maydis $[25,36$, 37]. On the other hand, the level of regulation of conidial germination was significantly different among these species; no conidia germinated in $B$. maydis $[25,36,37]$, a few conidia germinated in $M$. oryzae $[15,27]$, and a few conidia germinated in water but most conidia of Colletotrichum spp. germinated in nutrient-rich conditions $[18,25,36]$. In contrast, this cascade of $B$. cinerea seemed not to be involved in conidiation but affected conidial germination in pure water [21]. In $U$. maydis, both formation and germination of teliospores were also regulated by this cascade $[19,20,26]$. Therefore, the Stel1-Ste7-Fus3/Kss1-type MAPK cascade could regulate morphogenesis of sexual or asexual spores in the species mentioned above, although the regulated stage, spore formation or germination, differed depending on the species. 
In S. cerevisiae, Ste7 MEK is essential for signal transduction from Ste11 MEKK to Kss1/Fus3 MAPK [12, 38, 39]. However, Stel1 MEKK also acts upstream of another MAPK cascade, the Hog1-type MAPK cascade. In this pathway, called the "Shol branch," Stell MEKK transmits the signal to downstream proteins via Pbs2 MEK, not Ste7 MEK [40, 41]. On the other hand, previous studies indicated that this crosstalk of MAPK cascades should not occur in filamentous fungi, including plant pathogens, because Pbs2-type MEK in filamentous fungi lacks the proline-rich motif that is required for binding to the Shol sensor protein [42-44]. Hence, it is suggested that Ste7-type MEK may transmit all signals from Stell-type MEKK to Fus3/Kss1 MAPK, without any crosstalk with another MAPK cascade in a phytopathogen such as $C$. higginsianum, unlike in S. cerevisiae.

Overall, as a pleiotropic regulator of morphogenesis and plant infection, Ste7 MEK has highly conserved roles in phytopathogens, even those that are phylogenetically diverse. Moreover, there are some functional differences of this gene in several fungal species, which suggest that the regulation of Ste7 MEK varies and may be related to genetic distances between organisms.

\section{Conclusions}

It can be concluded that the C. higginsianum gene ChSte7 is involved in regulation of vegetative growth, appressorial formation, and postinvasive growth in host tissues. This is an important and conserved virulence factor affecting the infection of C. higginsianum on cruciferous plants.

\section{Competing Interests}

The authors declare that there is no conflict of interests regarding the publication of this paper.

\section{Acknowledgments}

This work was supported by grants funded by the National Natural Science Foundation of China (no. 31101399), the Specialized Research Fund for the Doctoral Program of Higher Education of China (no. 20110146120033), and the Program for Changjiang Scholars and Innovative Research Team in University of China (IRT1247).

\section{References}

[1] K. D. Hyde, L. Cai, P. F. Cannon et al., "Colletotrichum names in current use," Fungal Diversity, vol. 39, pp. 147-182, 2009.

[2] X. Yang, H.-X. Feng, and Y.-S. Yang, "Effects of silicon on flowering Chinese cabbage's anthracnose occurence, flower stalk formation, and silicon uptake and accumulation," Chinese Journal of Applied Ecology, vol. 19, no. 5, pp. 1006-1012, 2008.

[3] Y. Narusaka, M. Narusaka, P. Park et al., "RCH1, a locus in Arabidopsis that confers resistance to the hemibiotrophic fungal pathogen Colletotrichum higginsianum," Molecular PlantMicrobe Interactions, vol. 17, no. 7, pp. 749-762, 2004.
[4] R. J. O'Connell, C. Herbert, S. Sreenivasaprasad, M. Khatib, M.-T. Esquerré-Tugayé, and B. Dumas, "A novel ArabidopsisColletotrichum pathosystem for the molecular dissection of plant-fungal interactions," Molecular Plant-Microbe Interactions, vol. 17, no. 3, pp. 272-282, 2004.

[5] R. J. O'Connell, M. R. Thon, S. Hacquard et al., "Lifestyle transitions in plant pathogenic Colletotrichum fungi deciphered by genome and transcriptome analyses," Nature Genetics, vol. 44, no. 9, pp. 1060-1065, 2012.

[6] J. Kleemann, L. J. Rincon-Rivera, H. Takahara et al., "Sequential delivery of host-induced virulence effectors by appressoria and intracellular hyphae of the phytopathogen colletotrichum higginsianum," PLoS Pathogens, vol. 8, no. 4, Article ID e1002643, 2012.

[7] H. Takahara, A. Huser, and R. J. O’Connell, “Two arginine biosynthesis genes are essential for pathogenicity of Colletotrichum higginsianum on Arabidopsis," Mycology, vol. 3, no. 1, pp. 54-64, 2012.

[8] L. Liu, D. Zhao, L. Zheng et al., "Identification of virulence genes in the crucifer anthracnose fungus Colletotrichum higginsianum by insertional mutagenesis," Microbial Pathogenesis, vol. 64, pp. 6-17, 2013.

[9] M. Korn, J. Schmidpeter, M. Dahl, S. Müller, L. M. Voll, and C. Koch, "A genetic screen for pathogenicity genes in the hemibiotrophic fungus Colletotrichum higginsianum identifies the plasma membrane proton pump Pma2 required for host penetration," PLoS ONE, vol. 10, no. 5, Article ID e0125960, 2015.

[10] M. G. Wilkinson and J. B. A. Millar, "Control of the eukaryotic cell cycle by MAP kinase signaling pathways," FASEB Journal, vol. 14, no. 14, pp. 2147-2157, 2000.

[11] E. Nishida and Y. Gotoh, "The MAP kinase cascade is essential for diverse signal transduction pathways," Trends in Biochemical Sciences, vol. 18, no. 4, pp. 128-131, 1993.

[12] M. C. Gustin, J. Albertyn, M. Alexander, and K. Davenport, "Map kinase pathways in the yeast Saccharomyces cerevisiae," Microbiology and Molecular Biology Reviews, vol. 62, no. 4, pp. 1264-1300, 1998.

[13] D. Turrà, D. Segorbe, and A. Di Pietro, "Protein kinases in plantpathogenic Fungi: Conserved regulators of infection," Annual Review of Phytopathology, vol. 52, pp. 267-288, 2014.

[14] B. Errede, A. Gartner, Z. Zhou, K. Nasmyth, and G. Ammerer, "MAP kinase-related FUS3 from S. cerevisiae is activated by STE7 in vitro," Nature, vol. 362, no. 6417, pp. 261-264, 1993.

[15] J.-R. Xu and J. E. Hamer, "MAP kinase and cAMP signaling regulate infection structure formation and pathogenic growth in the rice blast fungus Magnaporthe grisea," Genes and Development, vol. 10, no. 21, pp. 2696-2706, 1996.

[16] K. S. Bruno, F. Tenjo, L. Li, J. E. Hamer, and J.-R. Xu, "Cellular localization and role of kinase activity of PMK1 in Magnaporthe grisea," Eukaryotic Cell, vol. 3, no. 6, pp. 1525-1532, 2004.

[17] S. J. Zhang, C. Jiang, Q. Zhang, L. L. Qi, C. H. Li, and J.-R. Xu, "Thioredoxins are involved in the activation of the PMK1 MAP kinase pathway during appressorium penetration and invasive growth in Magnaporthe oryzae," Environmental Microbiology, 2016.

[18] Y. Takano, T. Kikuchi, Y. Kubo, J. E. Hamer, K. Mise, and I. Furusawa, "The Colletotrichum lagenarium MAP kinase gene CMK1 regulates diverse aspects of fungal pathogenesis," Molecular Plant-Microbe Interactions, vol. 13, no. 4, pp. 374-383, 2000.

[19] M. E. Mayorga and S. E. Gold, "A MAP kinase encoded by the ubc3 gene of Ustilago maydis is required for filamentous growth 
and full virulence," Molecular Microbiology, vol. 34, no. 3, pp. 485-497, 1999.

[20] P. Müller, C. Aichinger, M. Feldbrügge, and R. Kahmann, “The MAP kinase Kpp2 regulates mating and pathogenic development in Ustilago maydis," Molecular Microbiology, vol. 34, no. 5, pp. 1007-1017, 1999.

[21] L. Zheng, M. Campbell, J. Murphy, S. Lam, and J.-R. Xu, "The BMP11 gene is essential for pathogenicity in the gray mold fungus Botrytis cinerea," Molecular Plant-Microbe Interactions, vol. 13, no. 7, pp. 724-732, 2000.

[22] X. Zhao, R. Mehrabi, and J.-R. Xu, "Mitogen-activated protein kinase pathways and fungal pathogenesis," Eukaryotic Cell, vol. 6, no. 10, pp. 1701-1714, 2007.

[23] J.-R. Xu, "MAP kinases in fungal pathogens," Fungal Genetics and Biology, vol. 31, no. 3, pp. 137-152, 2000.

[24] Y. Kitade, T. Sumita, K. Izumitsu, and C. Tanaka, "MAPKKencoding gene Ste7 in Bipolaris maydis is required for development and morphogenesis," Mycoscience, vol. 56, no. 2, pp. 150158, 2015.

[25] Y.-K. Kim, T. Kawano, D. X. Li, and P. E. Kolattukudy, "A mitogen-activated protein kinase kinase required for induction of cytokinesis and appressorium formation by host signals in the conidia of Colletotrichum gloeosporioides," Plant Cell, vol. 12, no. 8, pp. 1331-1343, 2000.

[26] F. Banuett and I. Herskowitz, "Identification of fuz7, a Ustilago maydis MEK/MAPKK homolog required for a-locusdependent and -independent steps in the fungal life cycle," Genes and Development, vol. 8, no. 12, pp. 1367-1378, 1994.

[27] X. H. Zhao and J.-R. Xu, "A highly conserved MAPK-docking site in Mst7 is essential for Pmk1 activation in Magnaporthe grisea," Molecular Microbiology, vol. 63, no. 3, pp. 881-894, 2007.

[28] X. Zhao, Y. Kim, G. Park, and J.-R. Xu, "A mitogen-activated protein kinase cascade regulating infection-related morphogenesis in Magnaporthe grisea," Plant Cell, vol. 17, no. 4, pp. 13171329, 2005.

[29] G. Li, X. Zhou, and J.-R. Xu, "Genetic control of infectionrelated development in Magnaporthe oryzae," Current Opinion in Microbiology, vol. 15, no. 6, pp. 678-684, 2012.

[30] M. Li, X. Gong, J. Zheng, D. Jiang, Y. Fu, and M. Hou, "Transformation of Coniothyrium minitans, a parasite of Sclerotinia sclerotiorum, with Agrobacterium tumefaciens," FEMS Microbiology Letters, vol. 243, no. 2, pp. 323-329, 2005.

[31] Y.-G. Liu and Y. Chen, "High-efficiency thermal asymmetric interlaced PCR for amplification of unknown flanking sequences," BioTechniques, vol. 43, no. 5, pp. 649-656, 2007.

[32] J. Sambrook, E. F. Fritsch, and T. Maniatis, Molecular Cloning: A Laboratory Manual (2nd Edition), Cold Spring Harbor Laboratory Press, New York, NY, USA, 1989.

[33] L.-P. Hamel, M.-C. Nicole, S. Duplessis, and B. E. Ellis, "Mitogen-activated protein kinase signaling in plant-interacting fungi: distinct messages from conserved messengers," The Plant Cell, vol. 24, no. 4, pp. 1327-1351, 2012.

[34] A. Schamber, M. Leroch, J. Diwo, K. Mendgen, and M. Hahn, "The role of mitogen-activated protein (MAP) kinase signalling components and the Ste12 transcription factor in germination and pathogenicity of Botrytis cinerea," Molecular Plant Pathology, vol. 11, no. 1, pp. 105-119, 2010.

[35] A. Sakaguchi, G. Tsuji, and Y. Kubo, "A yeast STE11 homologue CoMEKK1 is essential for pathogenesis-related morphogenesis in Colletotrichum orbiculare," Molecular Plant-Microbe Interactions, vol. 23, no. 12, pp. 1563-1572, 2010.
[36] K. Izumitsu, A. Yoshimi, D. Kubo, A. Morita, Y. Saitoh, and C. Tanaka, “The MAPKK kinase ChStell regulates sexual/asexual development, melanization, pathogenicity, and adaptation to oxidative stress in Cochliobolus heterostrophus," Current Genetics, vol. 55, no. 4, pp. 439-448, 2009.

[37] S. Lev, A. Sharon, R. Hadar, H. Ma, and B. A. Horwitz, "A mitogen-activated protein kinase of the corn leaf pathogen Cochliobolus heterostrophus is involved in conidiation, appressorium formation, and pathogenicity: diverse roles for mitogenactivated protein kinase homologs in foliar pathogens," Proceedings of the National Academy of Sciences of the United States of America, vol. 96, no. 23, pp. 13542-13547, 1999.

[38] A. M. Neiman and I. Herskowitz, "Reconstitution of a yeast protein kinase cascade in vitro: activation of the yeast MEK homologue STE7 by STE11," Proceedings of the National Academy of Sciences of the United States of America, vol. 91, no. 8, pp. 33983402, 1994.

[39] L. Bardwell, J. G. Cook, E. C. Chang, B. R. Cairns, and J. Thorner, "Signaling in the yeast pheromone response pathway: specific and high-affinity interaction of the mitogen-activated protein (MAP) kinases Kss1 and Fus3 with the upstream MAP kinase kinase Ste7," Molecular and Cellular Biology, vol. 16, no. 7, pp. 3637-3650, 1996.

[40] T. Maeda, M. Takekawa, and H. Saito, "Activation of yeast PBS2 MAPKK by MAPKKKs or by binding of an SH3-containing osmosensor," Science, vol. 269, no. 5223, pp. 554-558, 1995.

[41] V. Reiser, S. M. Salah, and G. Ammerer, "Polarized localization of yeast Pbs2 depends on osmostress, the membrane protein Shol and Cdc42," Nature Cell Biology, vol. 2, no. 9, pp. 620-627, 2000.

[42] D. C. Raitt, F. Posas, and H. Saito, "Yeast Cdc42 GTPase and Ste20 PAK-like kinase regulate Shol-dependent activation of the Hog1 MAPK pathway," The EMBO Journal, vol. 19, no. 17, pp. 4623-4631, 2000.

[43] K. Furukawa, Y. Hoshi, T. Maeda, T. Nakajima, and K. Abe, "Aspergillus nidulans HOG pathway is activated only by twocomponent signalling pathway in response to osmotic stress," Molecular Microbiology, vol. 56, no. 5, pp. 1246-1261, 2005.

[44] M. Krantz, E. Becit, and S. Hohmann, "Comparative analysis of HOG pathway proteins to generate hypotheses for functional analysis," Current Genetics, vol. 49, no. 3, pp. 152-165, 2006. 

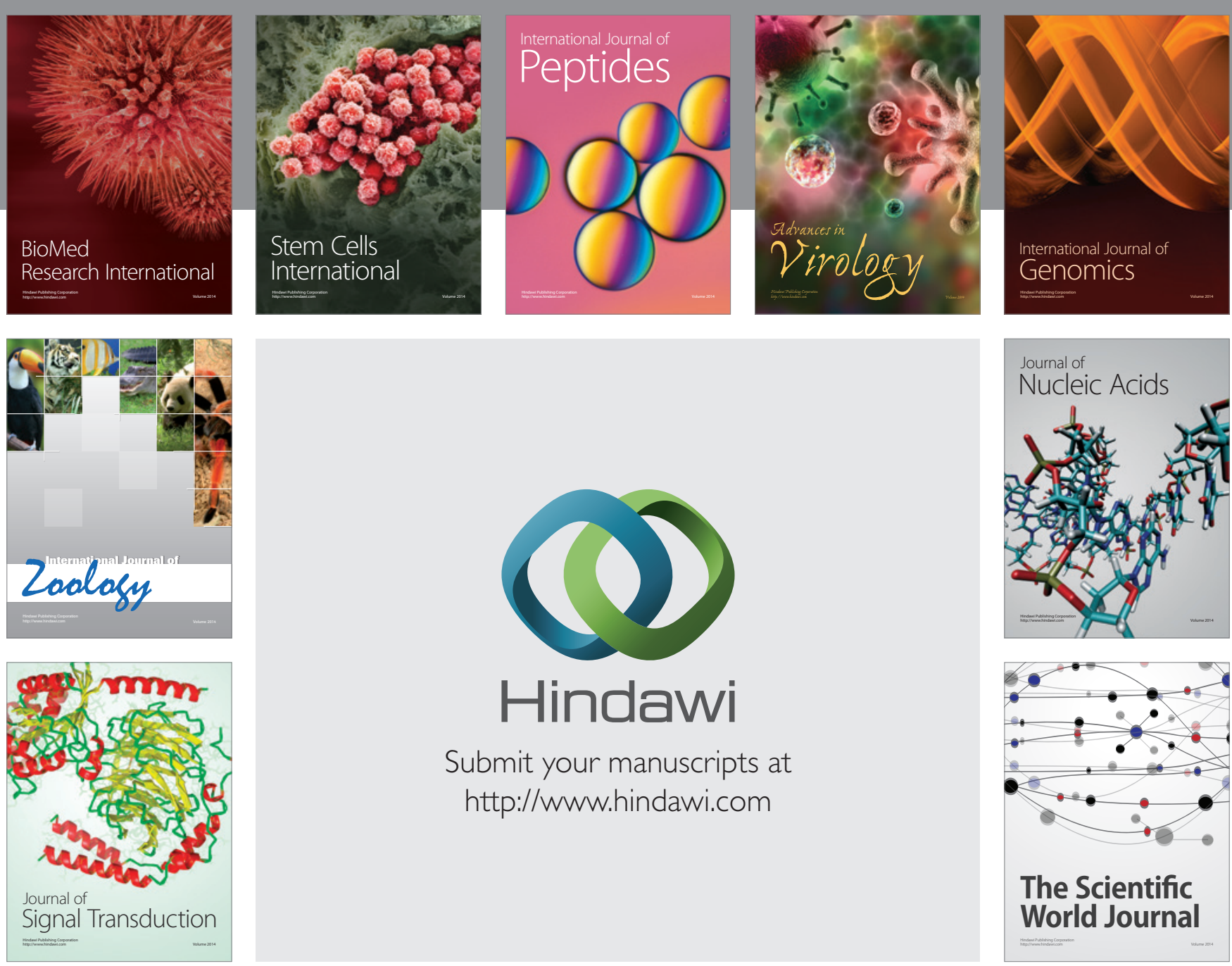

Submit your manuscripts at

http://www.hindawi.com
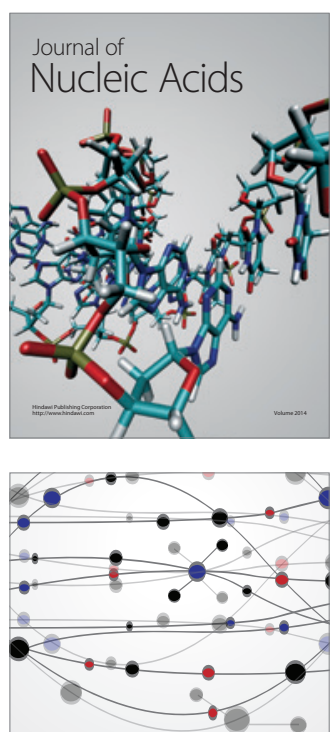

The Scientific World Journal
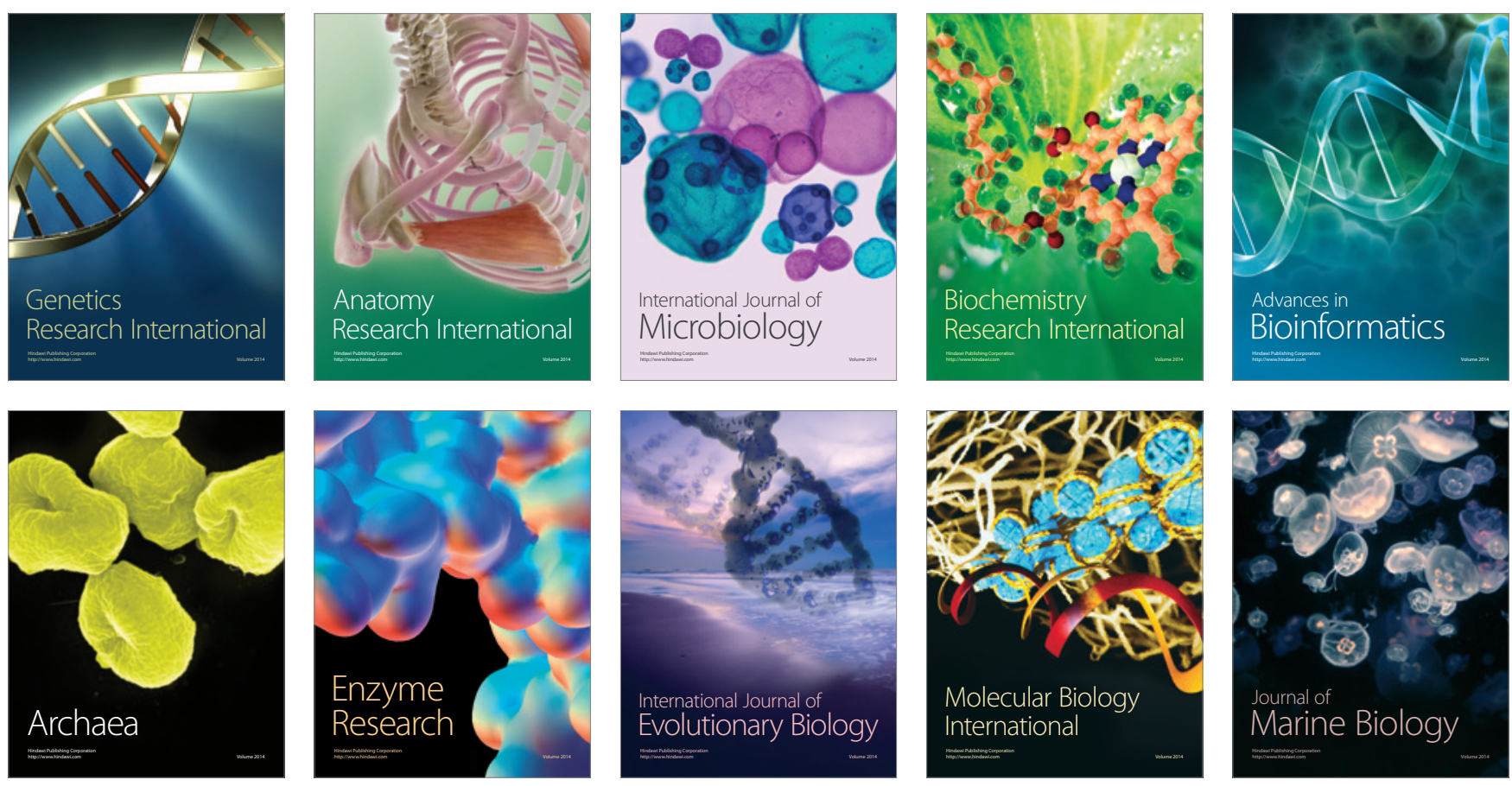